\title{
A brincadeira das crianças como experiência social de elaboração de conhecimentos acerca do mundo físico na Educação Infantil
}

\begin{abstract}
Resumo: Com o objetivo de compreender articulações entre as brincadeiras nas experiências sociais das crianças com a elaboração de conhecimentos acerca do mundo físico, relatamos uma experiência, a partir de uma pesquisa-ação, em um contexto de Educação Infantil, com 23 crianças, nível IV de um Centro Municipal de Educação Infantil e sua professora na cidade do Natal (RN). Partindo de compreensões teóricas acerca do brincar, dos objetivos previstos nas Diretrizes Curriculares Nacionais para a Educação Infantil e de práticas educativas por investigação, desenvolvemos duas sequências didáticas sobre o ciclo da chuva e da gravidade. As interpretações nos permitiram concluir que: as crianças desenvolveram o pensamento ao tomarem decisões, testarem hipóteses e sistematizarem suas compreensões para os fenômenos naturais que apareciam em suas brincadeiras; a Educação Infantil é um espaço de produção de saberes que valoriza as características da infância, possibilitando ao docente constituir-se pesquisador de suas práticas educativas.
\end{abstract}

Palavras-chave: Brincadeiras. Conhecimentos Científicos. Educação Infantil.

Experiências sociais.

\section{Children's games as a social experience of knowledge elaboration about the phisical world in the early childhood education}

Abstract: With the goal to understand the articulations among play in the children social experiences and the knowledge elaboration about the physical world, we report an experience, starting in an action-research, in the Early Childhood Education context witch twenty-three children and its teacher, of level IV at a Municipal Center for Early Childhood Education, at Natal city, RN. Based on theoretical understandings about playing, the objectives set forth in the Brazilian National Curriculum Guidelines for Early Childhood Education and educational research practices, we developed two didactic sequences that involved playing and investigative experiences about the rain cycle and the gravity. The interpretations allowed us to conclude that: children have developed thought by making decisions, testing hypotheses and systematizing, with different languages, their understandings of the natural phenomena that appeared in their games; the Early Childhood Education is a space for the production of knowledge that enriches the characteristics of childhood, while enabling to the teacher to become a researcher of their educational practices.

Keywords: Children's Games. Scientific Knowledge. Early Childhood Education. Social Experience. 


\section{Introdução}

$\mathrm{I}$

niciamos este texto, convidando ao leitor para observar por alguns instantes os registros fotográficos de uma criança da Educação Infantil, no pátio da sua unidade educacional:

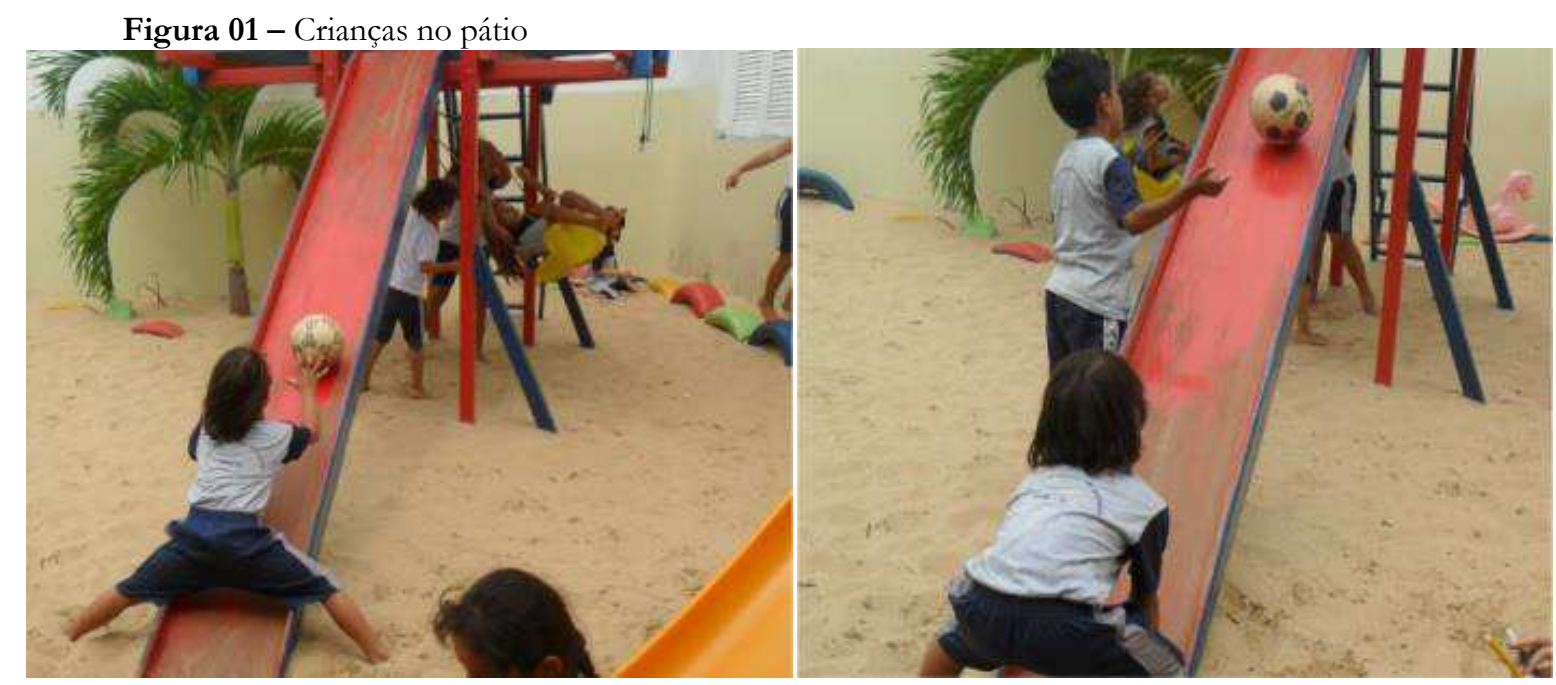

Fonte: Arquivo da pesquisa

Dentre as várias leituras que podem ser feitas, direcionamos nossas interpretações para as relações das crianças com o "brincar" de jogar bola e, ao mesmo tempo, o "experimentar suas hipóteses", ao testar diferentes distâncias de lançar a bola no escorregador, observando sua velocidade de queda.

Refletir acerca desta articulação entre a brincadeira e as experiências sociais das crianças na elaboração de conhecimentos acerca do mundo físico é nosso objeto de interesse nesta pesquisa. Ao observarmos as interações das crianças com os outros em seu cotidiano a partir de suas brincadeiras, pressupomos que é possível diversificar oportunidades para ampliarem suas aprendizagens à medida que constroem “[...] sentidos sobre a natureza e a sociedade, produzindo cultura”. (BRASIL, 2010, p. 12).

Considerando as Diretrizes Nacionais para a Educação Infantil - DCNEI (BRASIL, 2010) as instituições de Educação Infantil têm assumido as funções de Cuidar e Educar, considerando-as como processos complementares e indissociáveis para o desenvolvimento integral das crianças, em seus aspectos físico, psicológico, intelectual e social, complementando a ação da família e da comunidade. Nessa 
abordagem as crianças são valorizadas como sujeitos de direitos, com "acesso a processos de apropriação, renovação e articulação de conhecimentos e aprendizagens de diferentes linguagens, assim como o direito à proteção, à saúde, à liberdade, à confiança, ao respeito, à dignidade, à brincadeira, à convivência e à interação com outras crianças". (BRASIL, 2010, p. 18).

Com esse sentido, as propostas pedagógicas das instituições de Educação Infantil precisam prever a organização de tempos, espaços e materiais que atendam as especificidades de aprendizagem e desenvolvimento das crianças. Dentre elas, observamos que as crianças brincam e algumas brincadeiras são desafios às leis da natureza. Nesta direção, compreendemos que os profissionais da educação que "educam" e "cuidam" das crianças podem potencializar algumas brincadeiras em que são instigadas a resolverem desafios, elaborando e testando hipóteses de solução, compartilhando com os outros seus modos de ação. Com isso, a brincadeira pode-se constituir para as crianças, também, um tempo de apropriação e consolidação de novos saberes, cada vez mais complexos, na direção de explicações próximas às científicas.

Orientados por este pressuposto, objetivamos, por meio de uma experiência de pesquisa-ação com um coletivo de crianças de uma unidade de Educação Infantil da cidade de Natal (RN), compreender articulações entre as brincadeiras nas experiências sociais das crianças com a elaboração de conhecimentos acerca do mundo físico.

\section{Aporte Teórico}

O aporte teórico desse relato está organizado em três seções, inicialmente abordaremos compreensões de Educação Infantil, recorrendo principalmente aos documentos curriculares nacionais, por conseguinte, discorreremos sobre a importância da brincadeira na Educação Infantil e por fim, trataremos sobre a brincadeira e suas articulações com o aprender ciências.

\section{Compreensões acerca da Educação Infantil}

A inclusão da Educação Infantil na educação básica, como sua primeira etapa, é o reconhecimento de que a educação começa nos primeiros anos de vida e é essencial para o cumprimento de sua finalidade. Segundo o Art. 22 da Lei de Diretrizes e Bases da Educação Nacional - LDB, "a educação básica tem por finalidade desenvolver o educando, assegurar-lhe a formação comum indispensável para o exercício da cidadania e fornecer-lhes meios para progredir no trabalho e nos estudos posteriores" (BRASIL, 1996, p. 9). Nesta Lei estão incluídos os direitos das crianças com relação à educação, afastando a possibilidade de somente as atividades inerentes ao cuidado das crianças serem necessárias nessa fase da educação, fazendo dessa forma compreender que a instituição educacional é o lugar de continuidade da educação. Segundo as Diretrizes Curriculares Nacionais - DCNEI (BRASIL, 2010, p. 13), a Educação Infantil é "oferecida em creches e pré-escolas, às quais se caracterizam como 
espaços institucionais não domésticos que constituem estabelecimentos educacionais públicos ou privados que educam e cuidam de crianças de 0 a 5 anos de idade".

De acordo com a DCNEI (BRASIL, 2010, p. 26-27), as práticas pedagógicas que compõem a proposta curricular da Educação Infantil devem ter como eixos norteadores, as interações e a brincadeira, garantindo experiências que "incentivem a curiosidade, a exploração, o encantamento, o questionamento, a indagação e o conhecimento das crianças em relação ao mundo físico e social, ao tempo e à natureza". Em contextos de Educação Infantil observamos que as crianças brincam e em algumas brincadeiras podem experienciar princípios de leis da natureza. Nesta direção, pressupomos que é possível abordar brincadeiras também com a possibilidade de promover aprendizagens, de modo que "vivam intensamente o seu modo de ser criança, compreendendo a realidade que as cerca através do brinquedo" (DORNELLES, 2001, p. 102). Mas qual a importância da brincadeira para o desenvolvimento das crianças na Educação Infantil?

\section{Importância da brincadeira na Educação Infantil}

A brincadeira se constitui num procedimento fundamental para o desenvolvimento das crianças, contribuindo para elaboração de seus conhecimentos. Brincar é uma atividade na qual as crianças podem se expressar pelas ações e construir relações sociais com outros sujeitos. Segundo Dornelles (2001, p. 103) "estudos feitos sobre a história da infância nos mostram que a criança vê o mundo através do brinquedo". Isso mostra que a brincadeira é indispensável para o desenvolvimento das crianças e assim sendo, na instituição educacional a professora pode organizar coletivamente com os pequenos espaços que garantam a brincadeira.

Existem brinquedos e brincadeiras tradicionais, muitas delas possuem procedência dos povos que deram origem à nossa cultura (o índio, o branco e o negro). "Por sermos um país de muitos imigrantes, muitos dos grupos que para cá vieram, trouxeram consigo e com suas crianças vários jogos e brincadeiras de seus países de origem" (DORNELLES, 2001, p. 103), tais como: brincadeiras de subir em árvores, a peteca, pés de coco, perna de pau, jogos, trançados com barbante, adivinhações, berlinda, bolas de gude ou biloca, estátua, labirinto, par ou impar, pular corda, escravos de Jô, pular elástico, amarelinha, entre outras, podendo também variar o nome da brincadeira de região para região. Valorizar estas brincadeiras está em consonância com um dos objetivos da DCNEI (BRASIL, 2010, p. 19) que busca assegurar "a apropriação pelas crianças das contribuições histórico-culturais dos povos indígenas, afrodescendentes, asiáticos, europeus e de outros países da América". Em outro turno, "O reconhecimento, a valorização, o respeito e a interação das crianças com as histórias e as culturas africanas, afro-brasileiras, bem como o combate ao racismo e à discriminação"; (BRASIL, 2010, p. 21).

Parafraseando Paulo Freire quando revela que "um homem não aprende a nadar em uma biblioteca, mas na água" (FREIRE, 2011, p. 77), no caso das crianças, para que elas vivenciem diferentes formas de brincar é necessário que tenham um ambiente propício para as brincadeiras. E à medida que 
elas crescem e se desenvolvem, as brincadeiras vão se tornando mais elaboradas, pois as crianças tornamse capazes de assimilar as regras de um jogo mais complicado.

Kishimoto (1994, p. 109), argumenta que "o brinquedo coloca a criança na presença de reproduções: tudo o que existe no cotidiano, a natureza e as construções humanas. Pode-se dizer que um dos objetivos do brinquedo é dar à criança um substituto dos objetos reais, para que possa manipulá-los". Uma vez que as crianças passam um terço de seu dia na instituição educacional, faz-se necessário que esse tempo seja aproveitado da melhor maneira possível com o intuito de estimular e desenvolver suas potencialidades, enquanto brincam. Dessa maneira, é fundamental que o/a professor/a observe as ações e as brincadeiras como momentos propícios também para experiências de aprendizagem de conhecimentos do mundo natural e esteja atento/a a algumas brincadeiras com a de prática educativa que "incentivem a curiosidade, a exploração, o encantamento, o questionamento, a indagação e o conhecimento das crianças em relação ao mundo físico e social, ao tempo e à natureza". (BRASIL, 2010, p. 26).

Além do mais, num mundo cada vez mais urbanizado, no qual a indústria da informatização expõe brinquedos que afastam as crianças das brincadeiras criativas, a tendência é que muitas das brincadeiras tradicionais percam espaço nas preferências infantis. Dornelles (2001, p. 103), mostra que "diversos brinquedos eletrônicos estão sendo incorporados ao cotidiano infantil, tais como: carros com controle remoto, minigames e videogames, fazendo parte das novas tecnologias do brincar". Mesmo assim, a criatividade cultural e inestimável das crianças, não permite que elas abandonem o desejo de descobrir e se aventurar em sua imaginação. Muito pelo contrário, as crianças mostram-se criativas, ao ponto de fazerem com que um simples cabo de vassoura amarrado a uma corda, ou ainda o próprio corpo amarrado, se torne um verdadeiro pêndulo simples. Esse brinquedo criado pelas crianças, pode permitir por exemplo, que a professora o explore como material pedagógico significativo para a aprendizagem de princípios das leis da natureza, como o movimento oscilatórioº ${ }^{1}$.

\section{O conhecimento científico a partir de uma abordagem investigativa na educação infantil}

Como observamos, brincar é fundamental para o processo de desenvolvimento das crianças e é preciso que o/a professor/a tenha ciência que a brincadeira por elas desenvolvida quando estão em momentos livres, podem ser valorizadas nas experiências de aprendizagem de conhecimentos científicos, tornando esses espaços num laboratório de ciências ao ar livre.

$\mathrm{O}$ olhar curioso, investigativo do/a professor/a possibilita ver que existem algumas brincadeiras que são desafiadoras das leis da natureza, tão desafiadoras que podem ser perigosas sem a intervenção de um profissional da educação, por isso a necessidade de acompanhamento constante.

\footnotetext{
1 Também conhecido como Pêndulo de Newton, é um dispositivo que recebe esse nome por demonstrar empiricamente a conservação do momentum e da energia, leis físicas estudadas e demonstradas por Newton. Disponível em <http://efisica.if.usp.br/mecanica/curioso/historia/newton/>. Acessado em 28 jun. 2017.
} 
Segundo Dornelles (2001, p. 104 - 105) “à medida que as crianças ampliam suas experiências, seu corpo já não lhe basta para as brincadeiras".

E é dentro dessa perspectiva que defendemosa construção de conhecimentos acerca do mundo físico por meio da articulação das brincadeiras com as experiências sociais da Educação Infantil. A escolha por essa abordagem de aprendizagem se deu em função de aproveitar a curiosidade que é natural das crianças e permitir que elas interajam, explorem e experimentem o mundo natural, não ficando abandonadas a própria sorte, nem ficando restritos a uma manipulação ativista e puramente lúdica. Eles são inseridos em processos investigativos, envolvendo-se na própria aprendizagem, seguindo passos como a elaboração de hipóteses, a análise de evidências, o registro e a interpretação dos dados, a socialização dos resultados (CAMPOS; NIGRO, 1999; 2009, CARVALHO, 2006; 2013).

Nessa perspectiva, são desenvolvidas nas crianças várias habilidades tais como a abertura para refletir, observar, criar, decidir, praticar, ouvir, cooperar, socializar e comunicar a respeito de suas aprendizagens e atitudes de maneira cada vez mais sistematizada. A atividade de caráter investigativo é uma estratégia, entre outras, que o/a professor/a pode utilizar para diversificar sua prática no cotidiano da instituição educacional. Tal estratégia engloba atividades, que, centradas nas crianças, possibilitam o desenvolvimento da autonomia e da capacidade de tomar decisões, de avaliar e de resolver problemas, desenvolvendo conceitos (CAMPOS; NIGRO, 1999, 2009). Esse aprendizado irá colaborar para as crianças quando precisarem enfrentar desafios semelhantes às brincadeiras, só que em situações reais. E tendo vivenciado essa capacidade de enfrentar desafios, poderão ter diminuídas as intimidações diante destes.

Se o/a professor/a possibilita experiências na qual as crianças reflitam sobre seus atos e elaborem possíveis explicações para os questionamentos que formularam, contribuirá para que ampliem significados acerca do mundo físico, apropriando-se dos conhecimentos que experimentaram em suas ações. Dessa forma, podem elaborar conhecimentos através da interação no ato de brincar.

É importante para o desenvolvimento das crianças a disponibilidade de espaço, tempo e materiais para que elas possam aprender e desenvolver-se com suas brincadeiras. O papel do/a professor/a nesse sentido é o de nortear a construção desses conhecimentos e incentivar as brincadeiras enquanto as crianças estiverem no ambiente da Instituição de Educação. E através desse incentivo, é possível desenvolver atividades de caráter investigativo que proporcionem às crianças a interação com objetos diferentes e com as pessoas à sua volta que são outras crianças, os/as professores/as e as pessoas envolvidas na educação dela (DORNELLES, 2001).

Para favorecer a articulação das brincadeiras com as experiências sociais das crianças na elaboração de conhecimentos acerca do mundo físico, o/a professor/a propõe ou elabora coletivamente com as crianças um problema para investigação. A elaboração de hipóteses e o plano de trabalho são realizados em conjunto com as crianças, considerando diferentes métodos e formas de registro durante o processo investigativo (CARVALHO, 2006). Desse modo, pressupomos que o brincar pode também aproximar-se da natureza do trabalho científico. 


\section{Relatando as experiências}

O conhecimento que se pretendeu elaborar neste modelo de investigação é de natureza qualitativa orientada pela pesquisa-ação (THIOLLENT, 2011). Essa escolha se deu em função de uma das autoras ser a professora da turma escolhida para a investigação e, a partir dela, o relato da experiência. $\mathrm{O}$ contexto em que desenvolveu-se a atividade foi o Centro Municipal de Educação Infantil (CMEI) Professora Elaine do Nascimento Lopes, situado em Natal (RN). Participaram da ação a professora, uma das autoras, e as crianças do último ano da Educação Infantil, nível IV, totalizando 23 crianças, sendo 9 meninos com idade entre 4 anos e 5 anos e 14 meninas com idade entre 5 anos e 6 anos.

Entre os procedimentos de geração de dados ${ }^{2}$ optamos pela observação participante do tipo periférica (MACEDO, 2004) e como instrumento para o registro e relato dos dados, impressões e acontecimentos observados, utilizamos o Diário de Campo, assim como fotografias e gravações em áudio, posteriormente transcritas, para reter, além da própria lembrança seletiva dos investigados, reflexos da realidade observada.

Por configurar-se num estudo de intervenção, desenvolveu-se uma ação pedagógica junto aos participantes da pesquisa, no qual contemplou-se duas atividades investigativas para esses estudo: "formação da chuva", "se a bola sobe, ela também desce". Esse estudo também englobou avaliações antes das intervenções (o que sabemos) e avaliações após as intervenções (o que aprendemos sobre), por meio de cartazes com respostas, objetivando-se realizar um diagnóstico e acompanhamento do processo, que se apresenta de forma mais detalhada na sequência:

\section{I - Diagnóstico dos conhecimentos prévios: "o que sabemos sobre"}

$1^{\text {a }}$. Atividade Investigativa - Formação da chuva: com o objetivo de promover a compreensão dos estados físicos e o ciclo da água. As crianças foram instigadas a propor hipóteses e investigar sobre a problemática "de onde vem a chuva?"

$2^{\mathrm{a}}$. Atividade Investigativa - Se a bola sobe, ela também desce: com o objetivo de experimentar as leis da natureza, como a gravidade, inseridas nas brincadeiras desenvolvidas pelas crianças. Elas deveriam propor hipóteses e investigar sobre a problemática "porque a bola sempre desce quando a jogamos para cima? O que faz a bola descer à rampa"?

II - Intervenções Pedagógicas:

Para as intervenções pedagógicas, tomamos como base as DCNEI, em seu Art. $3^{\circ}$. quando indicam que

${ }^{2} \mathrm{~A}$ opção pelo termo geração de dados em detrimento de "coleta" tem como premissa o argumento compartilhado de Fritzen (2012, p. 59), pois "[...] o pesquisador não vai a campo para meramente colher dados, como se eles estivessem prontos, à sua espera. Ele gera registros, uma vez que sua presença em campo não é neutra e suas escolhas refletem a sua posição epistemológica". Da mesma maneira, quando analisamos a produção científica sobre Clubes, já a fizemos, interpretando, mediados pelas compreensões teóricas que compartilhamos dos coletivos que circulamos ideias e práticas. 
O currículo da Educação Infantil é concebido como um conjunto de práticas que buscam articular as experiências e os saberes das crianças com os conhecimentos que fazem parte do patrimônio cultural, artístico, ambiental, científico e tecnológico, de modo a promover o desenvolvimento integral de crianças de 0 a 5 anos de idade(BRASIL, 2009, grifo nosso).

Ao utilizar como estratégias da ação pedagógica, a observação, o registro e a análise destes para fundamentar o planejamento, duas atividades investigativas foram propostas.

\section{$1^{a}$. Atividade Investigativa - Formação da chuva}

Essa atividade partiu da vontade das crianças de tomarem banho de chuva, que repentinamente se formou enquanto brincavam na área externa. Como as crianças não estavam preparadas com vestimentas adequadas naquele momento, e assim ficariam molhadas no restante do tempo que estivessem no Centro, a professora pensou em contemplar essa brincadeira numa outra ocasião e de forma adequada. Assim encaminhou-as para uma área coberta, sendo questionada pelas crianças, por sua vez, contrariadas com essa atitude. Ao retornarem para a sala, a chuva era o assunto mais importante, com muitos questionamentos. A professora combinou com as crianças que poderiam brincar com as gotas que caiam no pergolado existente ao lado na sala. Dessa maneira elas coletaram água da chuva com recipientes de diferentes tamanhos, lavaram brinquedos, molharam as mãos e cabelos e respingaram uns aos outros. Foi um tempo de brincadeira com a fluidez da água, de invenção, da descoberta da temperatura e de outras sensações, experiências do brincar na chuva na direção do que enuncia a DCNEI (BRASIL, 2009), “o conhecimento de si e do mundo por meio das experiências sensoriais, expressivas e corporais para movimentação ampla, expressão da individualidade e respeito pelos ritmos e desejos da criança".

Com base nessa experiência, posteriormente desenvolveu-se a seguinte sequência didática:

a) roda de conversa para observar e registrar os conhecimentos prévios com a construção do cartaz "o que sabemos sobre";

b) observação do céu e suas características em vários lugares e momentos tais como em casa, na instituição educacional entre outros;

c) reflexão e relato para os colegas e para a professora, novamente escriba das observações;

d) observação do céu e banho de chuva no parque da instituição educacional;

e) relato do que estava acontecendo com registro;

f) apreciação do vídeo "Smilinguido - Um dia de chuva"3;

g) releitura do vídeo através do desenho explicando o que haviam observado no vídeo;

h) criação do Jornal do Final de Semana Chuvoso;

i) investigação do processo de evaporação com vasos (jarros) da hortinha da sala ${ }^{4}$ (figura 02);

${ }^{3}$ SMILINGUIDO - Dia de chuva: Disponível em: <https://www.youtube.com/watchẹv=1nCe8L3-PL8. Acessado 10 jul. 2017.

4 Para essa atividade a professora não permitiu que as crianças colocassem água nas plantas da hortinha da sala de aula por alguns dias, pois todas deveriam investigar e descobrir o que aconteceu com a água que foi colocada na horta nos dias anteriores. Três dias depois todas puderam observar os jarros de perto e discutirem entre si até descobrirem como a água saia dos vasos. A professora novamente foi escriba dos relatos. 
Figura 02-Crianças observando evaporação da água nos vasos/potes.



Arquivo da pesquisa

j) investigação de outras problemáticas (dando sequência ao processo investigativo): como o sol enche as nuvens de água, como o sol tira a água dos jarros, como a água chega até as nuvens?

1) aula expositiva dialogada sobre o ciclo da água;

m) exposição dos vídeos "Turminha do SAAE - água" e "O ciclo da água"5 ;

n) realização de registros com desenhos sobre o ciclo da água;

o) observação da evaporação da água da panela na cozinha da instituição educacional e posterior discussão do ocorrido;

p) registro e exposição sobre o ciclo da água, nas paredes do CMEI;

q) criação de um novo cartaz "o que aprendemos sobre".

Depois das intervenções pedagógicas, tendo como abordagem as atividades investigativas (CAMPOS; NIGRO, 1999; 2009) novamente as crianças responderem a problemática "de onde vem a chuva?". Esse registro se deu por meio de desenhos representativos em cartazes para posterior comparação com os desenhos do diagnóstico inicial, contendo os conhecimentos prévios. Dessa maneira observamos pistas da elaboração do conhecimento pelas crianças acerca do mundo físico a partir do que já conheciam.

\section{Interpretações da Experiência}

Dentre as respostas das crianças obtidas inicialmente, contempladas no cartaz "o que sabemos sobre de onde vem a chuva?" destacamos:

"O céu é escuro, tem muitas nuvens carregadas e tem um vento frio";

\footnotetext{
${ }_{5}^{5}$ TURMINHA DO SAAE - Água: Disponível em: <https://www.youtube.com/watch?̨v=cDFEIRSLmG8> Acessado em 10 jul. 2017. O ciclo
} da água: Disponível em: <https://www.youtube.com/watch?v=g26Wk4gpkws. Acessado em 10 jul. 2017. 
"Ah professora você já sabe! Deus tem um balde e derrama água nas nuvens e depois elas ficam bem juntinhas e chove";

"A chuva vem do céu";

"A chuva vem das nuvens";

"A chuva vem da Terra";

"A chwva é porque Deus chorou";

"É porque Jesus chorou e Deus bota um ventilador e tem um vento forte";

"Jesus chora e enche o balde, ai cai a chuva. Jesus bota água e a água vem da nuvem";

"É o choro do gigante".

Interpretamos que os conhecimentos que prevalecem, vem ao encontro com as leituras de mundo (FREIRE, 2011) o qual essas crianças vivenciam, denotando-se forte cunho religioso e de forças divinas e superiores. Carvalho (2013) chama a atenção para o fato do/a professor/a estar bastante atento/a aos conhecimentos prévios das crianças. Para a autora, "o problema e os conhecimentos prévios - espontâneos ou já adquiridos - devem dar condições para que os alunos construam suas hipóteses e possam testá-las procurando resolver o problema" (CARVALHO, 2013, p. 07). A partir daí, do que as crianças já sabem, é possível estabelecer um diálogo problematizador entre professor e crianças, inclusive, com a inserção de novos questionamentos. Segundo Lima e Loureiro, (2013, p. 24), "conversamos com as crianças, falando com elas sobre nossas ideias a partir das ideias que elas trazem". Por isso, torna-se fundamental que a linguagem do/a docente e das crianças estejam em sintonia e que os saberes trazidos pelas crianças, das suas vivências, sejam respeitados e valorizados, a fim de que a partir deles se amplie o processo de elaboração dos conhecimentos.

Com base nisso, a professora da turma norteou o processo respeitando e partindo dos saberes dos sujeitos para que esses pudessem compreender as mudanças e as descobertas a partir da investigação. As atividades desenvolvidas proporcionaram às crianças momentos nos quais elas puderam participar ativamente através das dinâmicas propostas, fazendo uso de novas palavras, de jogos e brincadeiras, sempre norteados pela abordagem investigativa.

Foram realizadas brincadeiras no pátio em dias de sol, mas também em dias de chuva. Nesta, com as crianças previamente preparadas, envolveu atividades livres voltadas ao plano da imaginação (SARMENTO, 2002), tais como: brincando na areia imaginando que estavam fazendo bolo de aniversário ou construindo castelos; jogando areia molhada umas nas outras, batendo os pés com força nas poças de água que se formavam. Já as brincadeiras que tiveram a intervenção direta da professora, contemplou-se a observação de onde vinha a água da chuva, da cor do céu, dos pingos caindo e atingindo o corpo. As crianças foram estimuladas a refletirem sobre o processo de evaporação, pois em suas falas lembraram-se de fatos reais do cotidiano, tais como: a roupa que seca no varal; a louça que seca na pia da cozinha (Figura 03). 
Figura 03 - Crianças brincando e observando a evaporação da água.

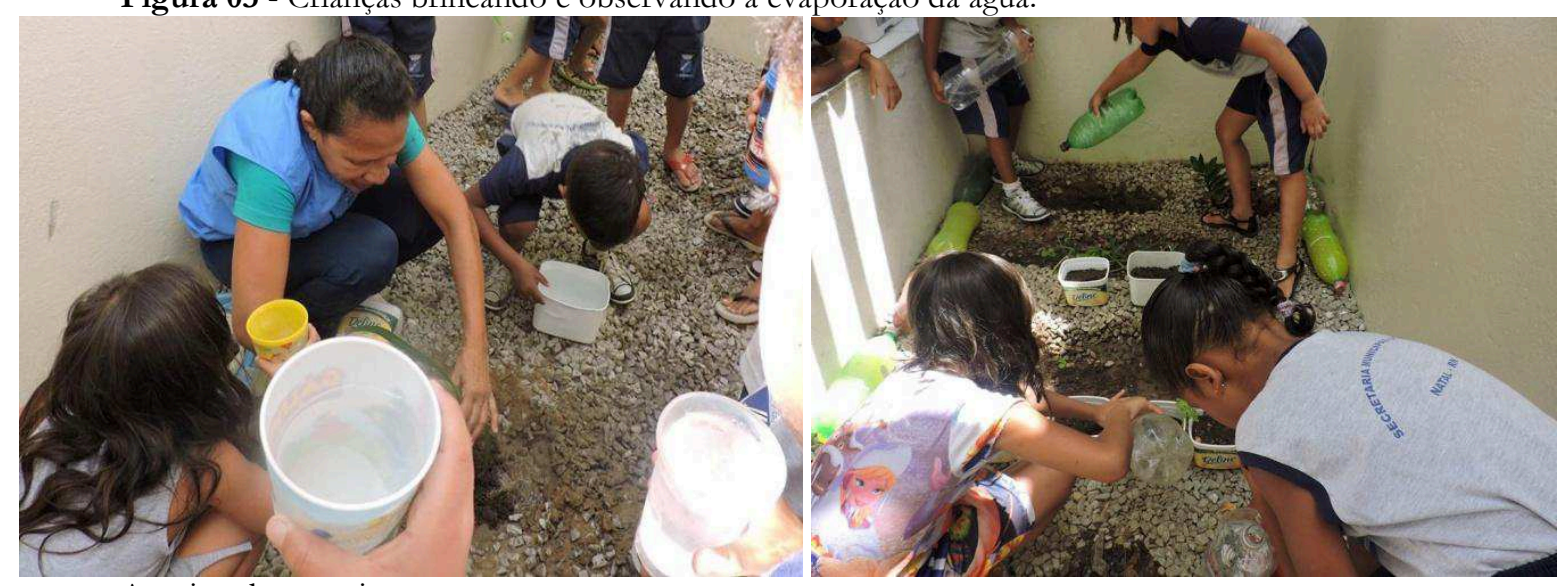

Arquivo da pesquisa

Esses achados vieram ao encontro dos saberes freireanos quando nos apontam que "a mudança de percepção, que se dá a partir da problematização de uma realidade concreta, no entrechoque de suas contradições, implica um novo enfrentamento do homem com sua própria realidade" (FREIRE, 2001, p. $33)$.

Como ponto alto das intervenções pedagógicas, durante a experimentação de simulação da formação das nuvens e da chuva por meio da água fervendo numa panela ${ }^{6}$, as crianças foram orientadas a observar a água entrar em ebulição e assim, sair em forma de vapor pelas bordas e alcançando, por sua vez, a tampa. Como a tampa da panela foi afastada, as crianças puderam observar que estava cheia de bolhas de água, que por sua vez retornavam para a panela em forma líquida. Ao final, cada criança pode falar sobre a experiência, pois havia o estímulo na atividade para dialogarem, no qual a expressão oral favorecia o pensamento ponderado e espontâneo, divergente, flexível e propício à invenção (SCHIEL; ORLANDI, 2009).

Em seguida, com o intuito de organizar a memória da ação desenvolvida, foram feitos os registros por meio de um desenho que representava e explicava como eles viam a formação da chuva após a investigação (Figura 04).Segundo Schiel e Orlandi (2009), por meio do registro a palavra também pode ser confirmada, remodelada, reescrita, colocada em relação a outros escritos.

${ }^{6}$ Por medidas de segurança, uma profissional da instituição educacional foi convidada para auxiliar nessa investigação, segurando a tampa da panela enquanto as crianças observavam o vapor subindo respeitando uma distância mínima necessária do fogão. 


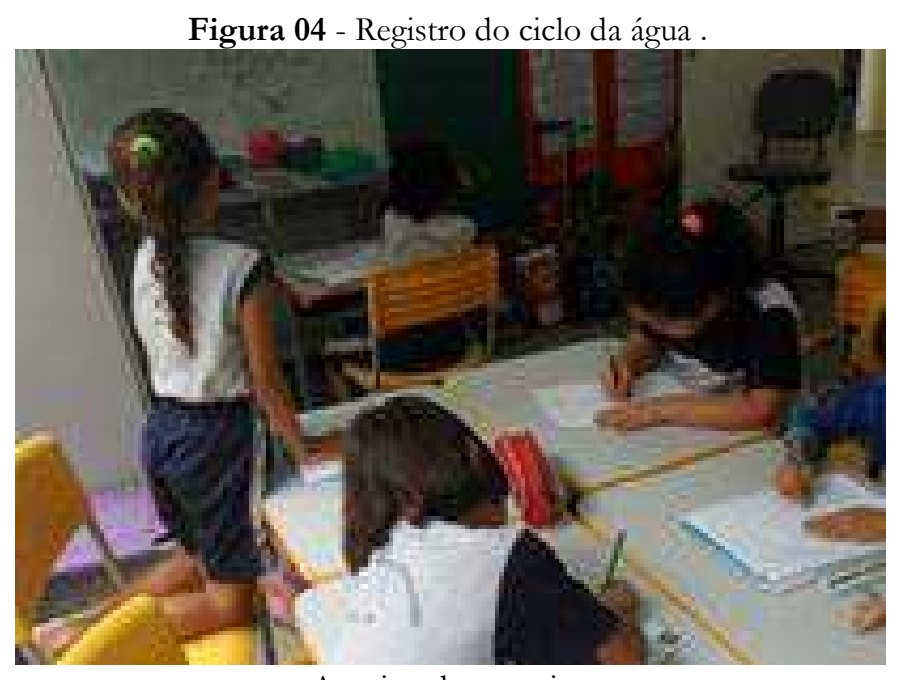

Arquivo da pesquisa

Contemplando a construção do cartaz "o que aprendemos sobre", as respostas das crianças após a culminância das intervenções foram as seguintes:

"A água sobe até chegar no céu e enche todas as nuvens de água e vem a chuva";

"A chuva vem das nuvens que se enche das águas das praias e do rio";

"A chuva pode nascer até das águas dos banheiros";

"A chuva também pode encher as nuvens com as águas das piscinas e das panelas";

"Aonde tem muita água é nas praias, então a praia forma mais nuvens";

"As panelas com água podem formar a chuva que vai para as nuvens";

"A chuva vem do céu porque a água que fica na terra vai subindo igual a panela da cozinha";

"Eu já sabia que a chuva vinha do céu e das nuvens";

"Eu sabia que o sol tirava a água das plantas para encher as nuvens e formar a chuva".

Como podemos observar as respostas das crianças, depois das atividades agora se mostram com mais aproximações das explicações científicas. Algumas das crianças ao serem lembradas das respostas produzidas anteriormente às atividades, ou seja, seus conhecimentos prévios, sorriam e negavam a autoria das falas iniciais. Nesse momento, é importante informar às crianças acerca de suas competências, valorizando seu esforço nesse processo de construção e apropriação do conhecimento. Outro aspecto importante a ser mencionado refere-se à observação de que fenômenos naturais estão ligados ao cotidiano, tais como: roupas secando no varal, chaleira com água no fogo liberando vapor pelo bico, os vasos da horta ou jarros presentes em casa com plantas e água, como destaca a DCNEI (BRASIL, 2010) com relação as práticas pedagógicas que compõem os eixos curriculares da Educação Infantil. 


\section{$2^{a}$. Atividade Investigativa - Se a bola sobe, ela também desce}

Durante as brincadeiras livres no parque, chamou a atenção da professora, as atividades das crianças junto à gangorra, ao escorregador, ao balanço e ao lançamento de uma bola para cima insistentemente. Ao questionar o motivo da repetição, as crianças responderam que queriam saber porque ela sempre desce ao ser lançada para o alto. A partir dessa curiosidade a professora percebeu um momento potencial para um processo de investigação e planejou uma sequência didática envolvendo a Gravidade descrita a seguir:

a) brincadeira de lançamento da bola para o alto e sobre a rampa inclinada várias vezes;

b) brincadeira de lançamento com outros objetos;

c) roda de conversa para refletir sobre as observações realizadas durante as brincadeiras.

d) aula expositiva dialogada sobre a interação da força gravitacional;

e) registro por meio de desenho explicando o que observaram sobre a força da gravidade;

f) apreciação de um vídeo intitulado "Gravidade" , para melhor compreensão da interação gravitacional;

g) criação do cartaz sobre "o que aprendemos sobre" o tema.

Depois das intervenções pedagógicas, tendo como abordagem as atividades investigativas (CAMPOS; NIGRO, 1999; 2009) novamente as crianças responderem a problemática porque a bola sempre desce quando jogamos ela para cima? O que faz a bola descer à rampa?”. Esse registro se deu por meio de desenhos representativos em cartazes para posterior comparação com os desenhos do diagnóstico inicial, contendo os conhecimentos prévios. Dessa maneira observamos pistas da elaboração do conhecimento pelas crianças acerca do mundo físico a partir do que já conheciam.

\section{Interpretações da Experiência}

Tendo como objetivo identificar a lei da natureza - força da gravidade, inserida nas brincadeiras desenvolvidas pelas crianças, elas deveriam pensar e investigar sobre a problemática "porque a bola sempre desce quando a jogamos para cima? O que faz a bola descer à rampa"?

Dentre as respostas obtidas inicialmente, contempladas no cartaz "o que sabemos sobre" temos:

"Porque os poderes de Deus sempre vão botar ela para baixo";

"Porque o vento assopra e ela vem para o chão";

"Porque ela não consegue voar";

"Porque quando a gente joga ela sempre vai descer";

"Por causa do vento ela desce";

"Olhe! Só sobem as bolas pequenas, as grandes sempre descem primeiro";

"Ela sempre desce porque não tem cola";

"Seria bom se ela sempre subisse, mas ela sempre desce";

"Tem uma força muito poderosa que sempre bota a bola para baixo".

\footnotetext{
7 Disponível em https://www.youtube.com/watch?v=hEMnT5P2agl. Acessado em 10 jul 2017.
} 
"Porque existe uma forsa poderosa";

"Porque nós também descemos";

"Porque a bola não consegue fazer força e segurar no escorregador, ai ela cai";

"Quando eu jogo ela com força ela vai mais um pouquinho, depois ela desce, mas eu não sei por que ela não quer ficar lá em cima";

"Sempre quando a pessoa joga uma bola ela desce".

Nessa atividade as respostas das crianças aproximaram-se da resposta científica, pois sem conhecer a força da gravidade, a maioria percebeu que há uma força que tende a fazer os objetos que são arremessados retornarem à terra. No entanto, como podemos observar, alguns ainda explicaram a partir do transcendental, citando Deus como resposta.

Ao observarmos essas predefinições, recorremos a Martins (2010), quando defende que entre as preocupações dos professores que trabalham com as Ciências da Natureza, uma delas deve ser o uso correto dos conceitos científicos, que necessitam ser abordados tanto pelos professores em sala de aula de maneira adequada. O/A professor/a ao perceber esse momento, seleciona atividades que contribuam e possibilitem essa construção, permitindo que as crianças também percebam que o conhecimento não se dá apenas baseado no conhecimento prévio e que a linguagem modifica a partir da inserção de novas aprendizagens, nos mais diversificados contextos. Conforme Martins (2010, p.12), "a linguagem científica não é a linguagem cotidiana, e a percepção de que se trata de contextos diferenciados é de fundamental importância no processo (dialógico) de ensinar e aprender Ciências".

E assim, após essa geração de dados iniciais, novamente foram desenvolvidas Intervenções Pedagógicas tendo como abordagem o brincar e suas relações com a Investigação (CAMPOS; NIGRO, 1999; 2009, CARVALHO, 2006; 2013). Por entendermos que as crianças veem o mundo através das brincadeiras, sendo esta indispensável para o desenvolvimento das crianças (DORNELLES, 2001), o lúdico prevaleceu nessas intervenções.

Foram realizadas brincadeiras no parque e durante as mesmas, as crianças foram percebendo a existência de uma força que atraia a bola e outros objetos para o chão (Figura 05). 
Figura 05 - Brincadeiras que desafiam a gravidade

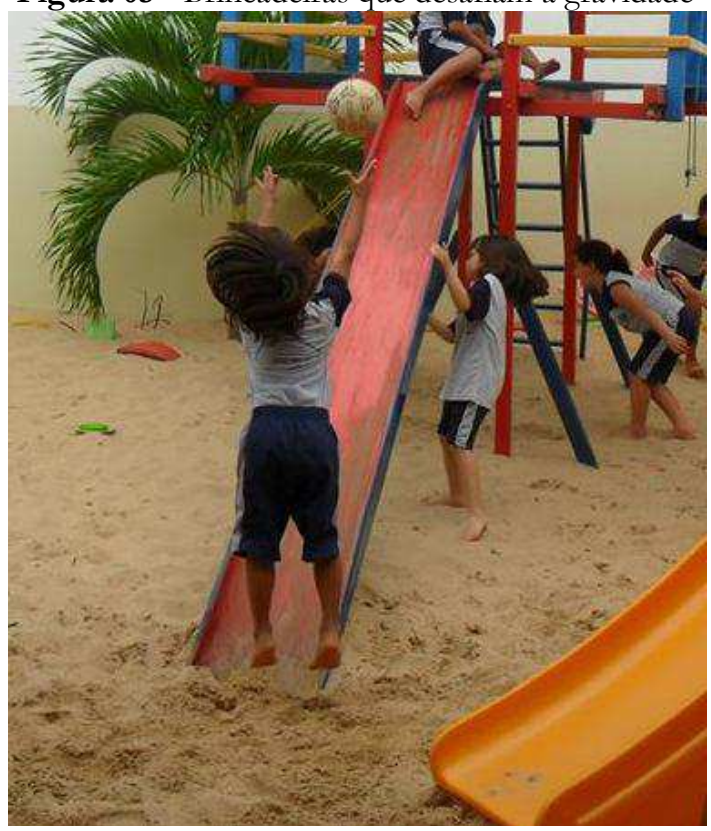

Arquivo da pesquisa

A mesma brincadeira foi realizada utilizando-se outros brinquedos diferentes para facilitar a percepção das crianças para o fenômeno da força que atrai os corpos para a terra. Entre eles estavam: o lançamento de carrinhos na rampa do escorregador em tamanhos diferentes para ver quem descia mais rápido; o salto das crianças da rampa do escorregador sobre um monte de areia; o dependurar-se no balanço de cabeça para baixo (Figura 06). Enfim variadas explorações com diferentes formas, maneiras, tamanhos, permitindo a descoberta nos brinquedos do parque, na direção do que prevê as DCNEI (BRASIL, 2009), experiências para recriar, em contextos significativos, relações quantitativas, medidas, formas e orientações espaço/temporais.

Figura 06 - Brincadeiras que desafiam a gravidade

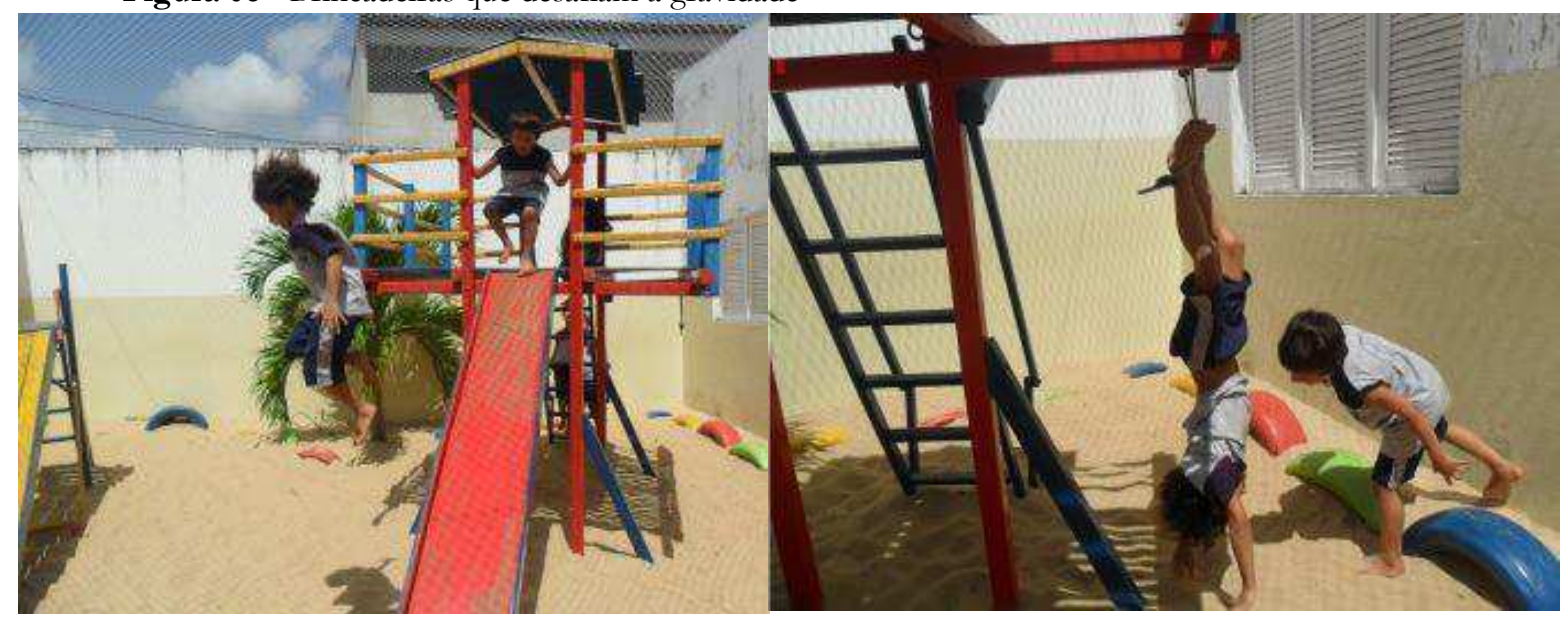

Fonte: Arquivo da pesquisa 
Essas brincadeiras repetitivas com outros objetos e a ação da professora fazendo-as lembrar-se de outras e das atividades desenvolvidas sobre os movimentos da Terra ao redor do Sol ajudaram a mudar a percepção das crianças. Todo esse movimento vem ao encontro de Capechi (2013, p. 24), quando nos aponta que "é preciso que os professores proponham a seus alunos um olhar diferenciado às situações que costumam vivenciar no cotidiano".

E dessa forma as crianças enfrentaram a gravidade, força de interação que tende a devolver tudo e todos ao seio da Terra. No momento das aulas expositivas dialogadas, a respeito da interação da força da gravidade sobre os corpos na face da terra, as crianças mostraram-se motivadas, pois as informações agora pareciam fazer sentido às crianças. Ao final das intervenções, diante dos conhecimentos elaborados, cada criança pode falar e registrar sobre a problemática inicial, permitindo assim a construção do cartaz "o que aprendemos sobre":

"Que existe a força da gravidade na terra e puxa a bola para baixo";

"Que existe uma força que puxa a bola para baixo e ela desce";

"A força da gravidade empurra tudo para baixo";

"Por que essa forca existe para segurar tudo que tem na terra";

"Porque a força da gravidade existe, se ela não existir as coisas ficam voando como as follhas";

"É perigoso ficar debaixo de plantas grandes porque as frutas podem cair e macbucar a cabeça";

"A força da gravidade não pode com o avião porque ele não cai";

"A força da Gravidade existe, mas é invisivel";

"Eu sei que a lua fica perto da Terra e lá no alto";

"A força da gravidade é forte e ajuda o Sol para ele não bater na Terra";

"Eu aprendi que existe uma força da gravidade para puxar as coisas para o chão";

"A força que sempre bota a bola para baixo é a gravidade".

A partir desta intervenção foi possível perceber no comportamento das crianças o quanto elas são observadoras e criativas. Capazes de enfrentar grandes riscos e superar a própria força para realizar descobertas. Elas acreditam na própria potencialidade e enfrentam seus medos com coragem. As crianças sabiam da existência de uma força poderosa, no entanto nunca tinham ouvido falar dela, mas quando foram incitadas a testar e sentir a presença da força não se intimidaram, pelo contrário, enfrentaram o risco sem medo de aprender e compartilhar conhecimento. Para Freire (2011, p. 10), não é diferente, pois "o homem substitui o envoltório protetor do meio natural por um mundo que o provoca e desafia, num comportamento ambíguo, enquanto ensaia o domínio técnico desse mundo, tenta voltar a seu seio, imergir nele, enleando-se na indistinção entre palavra e coisa".

Nesse momento é importante como ressalta Capecchi (2013), fazer uma discussão após a realização das atividades, sendo essencial para que as ações realizadas pelas crianças possam ser retomadas e analisadas por elas. E como podemos observar nas respostas construídas pelas crianças, elas 
conseguiram transpor os conhecimentos da cultura primeira, ou seja, o conhecimento prévio, para a cultura elaborada, mais próxima das explicações científicas (DELIZOICOV; ANGOTTI; PERNAMBUCO, 2003).

Essa superação pelas crianças se deu de forma mais fácil, pois já tinham uma noção de que existia uma força que puxava os corpos para a terra, mas não sabiam do que se tratava. Ao observar ao final as respostas, o conceito Força da Gravidade já se faz presente no vocabulário de algumas dessas crianças. Portanto, na experiência de brincar e investigar a ênfase não está no acúmulo de conceitos sem sentido, mas sim em proporcionar um ambiente educativo que leve as crianças à interação com o objeto de estudo, a elaborar hipóteses e testá-las, a discutir suas ideias com colegas e professores. É uma atividade que permite que "os sujeitos vão construindo ideias, às vezes conceitos, às vezes um conjunto mais difuso de pensamento" (DELIZOICOV; ANGOTTTI; PERNAMBUCO, 2003, p. 132).

Por conseguinte, a expectativa não é a de que as crianças pensem ou se comportem como pequenos cientistas, mas sim visa olhar para o brincar com potência, também, para uma intencionalidade no planejamento de atividades de investigação na Educação Infantil, favorecendo o diálogo das suas experiências e dos seus saberes com os conhecimentos que aproximam-se dos saberes científicos,na direção, do que prevê as DCNEI (BRASIL, 2009), a curiosidade, exploração, encantamento, questionamento, indagação e conhecimento em relação ao mundo físico e social, ao tempo e à natureza.

\section{Considerações finais}

$\mathrm{Na}$ experiência que relatamos no contexto de uma Educação Infantil objetivamos compreender articulações entre as brincadeiras nas experiências sociais das crianças com a elaboração de conhecimentos acerca do mundo físico.

Com o desenvolvimento das duas sequências didáticas notamos que as crianças se envolveram, a partir de brincadeiras, com as investigações propostas acerca de fenômenos da natureza, como a produção da chuva e o efeito da gravidade. São relevantes as evidências sobre a participação no diálogo com a troca de ideias no coletivo de crianças, a partir das hipóteses geradas quando desafiadas com situaçõesproblemas.

A metodologia desenvolvida proporcionou às crianças manipularem e explorarem os objetos sugeridos nas ações, também, de forma lúdica e valorizando as características dos seus modos de brincar. $\mathrm{E}$ as descobertas, evidenciadas na comunicação com as outras crianças e adultos, permitiram observarmos como, brincando, elas fazem tentativas de entenderem porque os fenômenos acontecem.

Nas atividades propostas, interpretamos que as crianças complexificaram suas explicações acerca do mundo físico e desenvolveram o pensamento ao tomaram decisões, testarem hipóteses e sistematizarem, com diferentes linguagens, suas compreensões para os fenômenos naturais que apareciam em suas brincadeiras. 
Desenvolver uma experiência com sequências didáticas investigativas, visando a elaboração pelas crianças de conceitos acerca do mundo físico, enquanto brincam, nos permitiu concluir que a Educação Infantil é um espaço de produção de saberes que valoriza as características da infância, ao mesmo tempo em que possibilita ao docente constituir-se pesquisador de suas práticas educativas, também, no campo de conhecimentos das ciências da natureza.

\section{Referências}

BRASIL. Lei de Diretrizes e Bases da Educação Nacional. Lei no 9.394, de 20 de dezembro de 1996. Disponível em: <http://portal.mec.gov.br/arquivos/pdf/ldb.pdf>. Acesso em 06 set. 2015.

BRASIL. Ministério da Educação. Secretaria de Educação Básica. Diretrizes curriculares nacionais para a educação infantil. Secretaria de Educação Básica. Brasilia : MEC, SEB, 2010.

BRASIL. Ministério da Educação. Conselho Nacional de Educação. Parecer CNE/CEB n ${ }^{\circ}$ 05/2009, aprovado em 17/12/2009. Disponível em: goo.gl/2V96Zk. Acesso em: 04mar 2018.

CAMPOS, Maria Cristina Cunha; NIGRO, Rogério Gonçalves. Didática das Ciências: o ensino aprendizagem como

investigação. São Paulo: FTD, 1999.

CAMPOS, Maria Cristina Cunha; NIGRO, Rogério Gonçalves. O ensino-aprendizagem como investigação. São Paulo, FTD, 2009.

CAPECCHI, Maria CandidaVarone de Morais. Problematização no ensino de Ciências. In: CARVALHO, Anna Maria Pessoa de. (Org.). Ensino de ciências por investigação: condições para implementação em sala de aula. São Paulo: Cengage Learning. 2013, p.21-39.

CARVALHO, Anna Maria Pessoa de. Las practices experimentales en el proceso de enculturación cientifica. In: GATICA, Mario Quintanilla; ADÚRIZ-BRAVO, Agustin (Ed). Enseñar ciencias en el Nuevo milenio: retos e propuestas. Santiago: Universidade católica de Chile, 2006.

CARVALHO, Anna Maria Pessoa de, et al. Ensino por Investigação: condições para implementação em sala de aula.São Paulo: Cengage Learning, 2013.

DELIZOICOV, Demétrio.; ANGOTTI, José André; PERNAMBUCO, Marta Maria.Ensino de Ciências: fundamentos e métodos. São Paulo: Cortez, 2003.

DORNELLES, Leni Vieira. Na escola infantil todo mundo brinca se você brinca. In CRAIDY, Carmem; KAERCHER, Gládis Elise da Silva. Educação Infantil: pra que te quero? Porto Alegre: Artmed, 2001. p. 101-108.

FREIRE, Paulo.Educação e mudança. 24a ed. Rio de Janeiro: Paz e Terra. 2001.

FREIRE, Paulo. Pedagogia do Oprimido. 50ª ed. Rio de Janeiro: Paz e Terra, 2011. 
FRITZEN, Maristela Pereira. O olhar da etnografia no fazer pesquisa qualitativa: algumas reflexões teórico-metodológicas. In: FRITZEN, Maristela Pereira; LUCENA, Maria Inêz Probst. O olhar da etnografia em contextos educacionais: interpretando práticas de linguagem. Blumenau: Edifurb, 2012. p.55-72.

KISHIMOTO, Tizuko Morchida. O jogo e a educação infantil. Perspectiva, Florianópolis, v. 12, n. 22, p. 105-128, jan. $1994 . \quad$ ISSN 2175-795X. Disponível em: $<$ https://periodicos.ufsc.br/index.php/perspectiva/article/view/10745/10260>. Acesso em 20 abr. 2017.

LIMA, Maria Emília Caixeta de Castro; LOUREIRO, Mairy Barbosa. Trilha para Ensinar Ciências para Crianças. Belo Horizonte, MG: Fino Traço, 2013.

MACEDO, Roberto Sidnei.A Etnopesquisa Crítica e Multirreferencial nas Ciências Humanas e na Educação. Salvador: EDUFBA, 2004.

MARTINS, André Ferrer Pinto. Palavras, textos \& contextos. In: PAVÃO, Antônio Carlos(Coord.). Coleção Explorando o Ensino: Ciências: ensino fundamental. v. 18. Brasília: Ministério da Educação, Secretaria de Educação Básica, 2010, p. 11-24.

SARMENTO, Manuel J. Imaginário e culturas da infância. Texto produzido no âmbito das atividades do Projeto "As marcas dos tempos: a interculturalidade nas culturas da infância". Projeto POCTI/CED/2002.

SCHIEL, Dietrich; ORLANDI, Angelina Sofia. Ensino de Ciências por investigação. Centro de Divulgação Científica e Cultural. USP, 2009. Disponível em http://www.cdcc.usp.br/maomassa/Livros/livro09/livro09Documentos/livro_enscien09.pdf. Acesso em 19 nov. 2015.

THIOLLENT, Michel. Metodologia da Pesquisa-ação. 18.ed.São Paulo: Cortez; 2011.

ROBREDO, Jaime. Documentação de hoje e de amanhã. Brasília, DF: Associação dos Bibliotecários do Distrito Federal, 1986. 398p. 